\title{
CDISC Huntington's Disease Therapeutic Area User Guide Version 1.0
}

National Cancer Institute

\section{Source}

National Cancer Institute. CDISC Huntington's Disease Therapeutic Area User Guide

Version 1.0. NCl Thesaurus. Code C161466.

The 1.0 version of the CDISC Huntington's Disease therapeutic area user guide. 